\title{
Visual disturbances after missile head injuries
}

\author{
ADELOLA ADELOYE \\ Neurosurgery Unit, University of Ibadan, Nigeria, West Africa
}

Disturbances of vision after head injury, both in war and in peace, have been recognized for a long time (Small, I96I); they were observed after gunshot wounds of the head during the Russo-Japanese war (Inouye, 1909), the first world war (Holmes and Lister, I916; Wilson, I917; Hine, 1918), and the second world war (Cross, I945; Skeoch, I945; Symonds, 1945; Calvert, 1947; Jepson and Whitty, 1947). At University College Hospital, Ibadan, Nigeria, we dealt with 250 patients with missile head wounds during the Nigerian civil war; 3 I of these patients ( 28 soldiers and 3 civilians) developed disturbances of vision and a brief analysis of the visual lesions encountered forms the subject of this paper.

\section{Patients}

Most of the soldiers with missile head wounds seen at the University College Hospital (UCH) Ibadan had been brought in from the hospitals or medical reception stations close to the war-front; the others came later to the hospital when they were ambulant and otherwise reasonably well, and were examined at the neurosurgical unit some time after the initial head wound had been received. Some of the civilian patients had been shot with game guns in hunting accidents or deliberate attacks, and the rest had received head wounds in the combat areas of the civil war. In the series as a whole, the average interval between wounding and presentation at the hospital was about Io days.

As far as is known, the $3^{1}$ patients with visual disturbance had had normal vision before being injured. They were all assessed clinically and treated subsequently at the neurosurgical and ophthalmological units. Fifteen were lost to follow-up as a result of troop movements during and after the war and sixteen were followed up for from I month to 3 years.

\section{Findings}

I. GENERAL

The 3 I patients with disturbances of vision were all males, their ages ranging from 18 years to 45 .

Sixteen wounds were inflicted by metallic fragments from hand grenades, mortar bombs, and shell explosions and thirteen by high velocity bullets; in the remaining two, the nature of the missile could not be ascertained.

Eighteen wounds were of the penetrating variety, eight were glancing or tangential, three were through-and-through, one involved the scalp alone, and one was unclassified because the wound had been treated surgically elsewhere. 
The distribution of the wounds is shown in Fig. I.

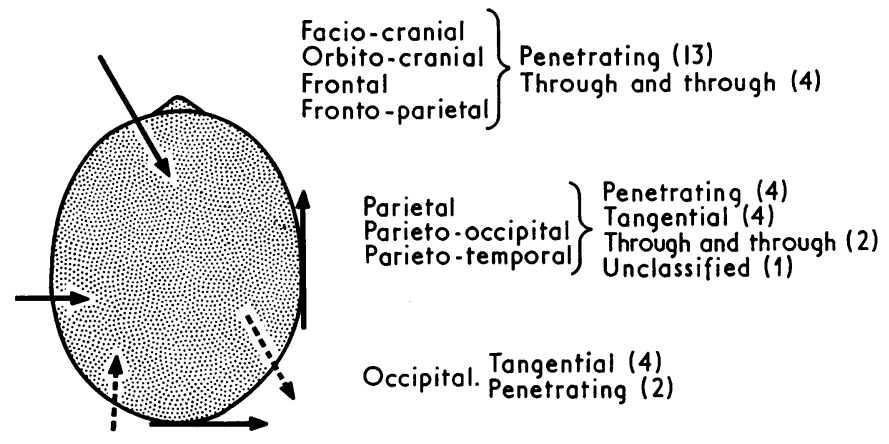

FIG. I Distribution of $3 \mathbf{I}$ missile head wounds. Tangential skull wounds (8), penetrating brain wounds (19), through-andthrough brain wounds (3), unclassified $(\mathbf{1})$.

\section{TYPES OF VISUAL DEFEGTS ENGOUNTERED}

The visual disturbances resulted from derangement of the anatomy of the visual pathway (23), neuromuscular abnormalities (3), and 'poor vision' associated with the post-concussional syndrome (3). There was one instance of hysterical blindness and, in one patient with post-traumatic epilepsy, an aura of amaurosis was a constant phenomenon.

\section{(a) Defects of visual pathway}

These are summarized in the Table. Most of the defects were associated with orbitofacio-cranial injuries; these were mostly on the left side of the face, and most of the damaged globes were thus on the left side.

Table Defects of visual pathway

\begin{tabular}{lll}
\hline Lesion & & Number of cases \\
\cline { 1 - 1 } Damaged globe & & I I (one bilateral) \\
Globe perforation with optic atrophy & I \\
Optic atrophy & I \\
Optic atrophy and 3rd nerve palsy & I \\
Globe perforation with homonymous hemianopia & & 4 \\
Homonymous hemianopia & & \\
Cortical blindness & 23 \\
\hline Total &
\end{tabular}

Of the ten patients with unilateral damage or destruction of the globe, two who had wounds due to high velocity bullets had symptoms of disturbed vision in the other apparently normal and intact eye.

The badly damaged globe was surgically removed in six patients; the other globes, which were not badly damaged but neatly perforated usually by tiny shrapnel fragments, were left alone. Two of the globes in the latter category ultimately sank into the orbits (phthisis bulbi). After evisceration of the globe, all but two of the patients were fitted with prostheses. In one the socket was contracted, and in the other the orbital margin was so badly shattered that a prosthesis could not be accommodated. The standard treatment of the cranial wound was debridement, in the course of which intracranial haematomata were evacuated with much benefit to those with neurological defects. 
The three cases of optic atrophy were unilateral; two were associated with penetrating brain wounds by high velocity bullets, and the third was due to metallic fragments from a hand grenade. The bullets passed close to the anatomical site of the optic nerve and either directly destroyed it or damaged it as a result of the cavitation phenomenon characteristic of high velocity missiles. In the third case, which was associated with shrapnel from a hand grenade, cerebral carotid angiography suggested that the tiny fragment had also interfered with, and probably damaged, the ipsilateral ophthalmic artery (Fig. 2).
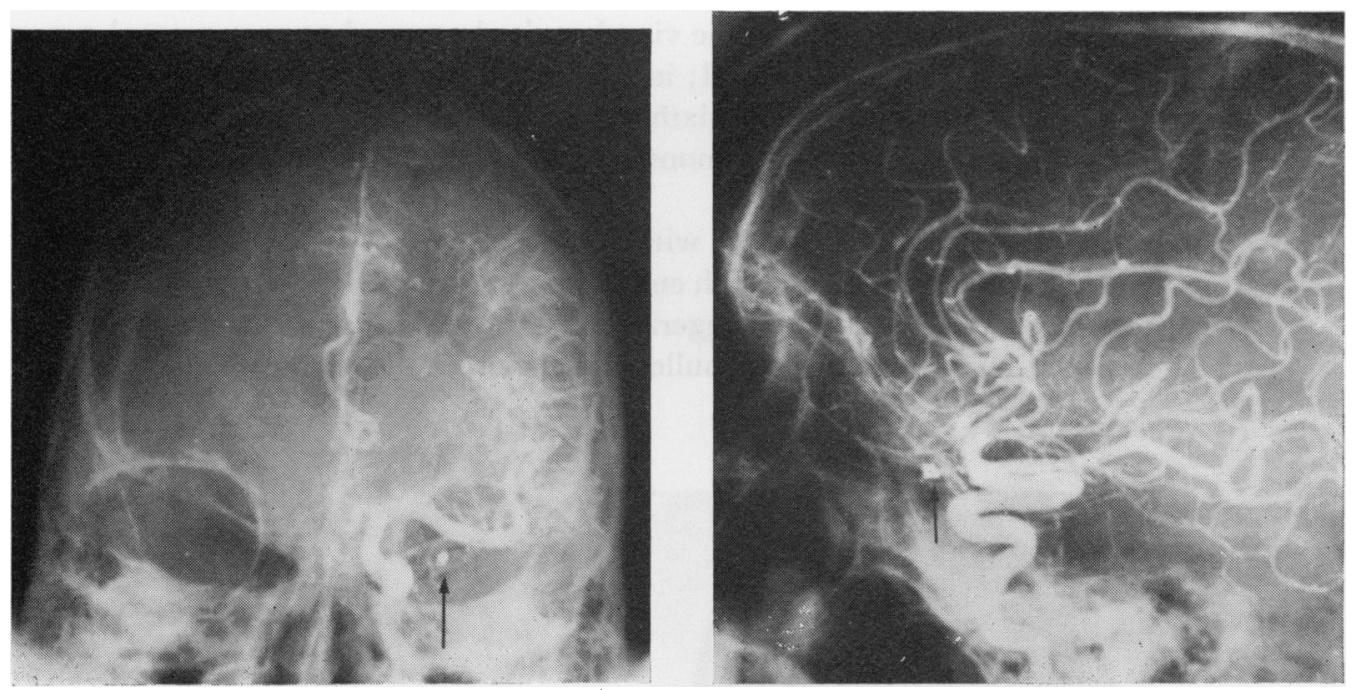

FIG. 2 Antero-posterior $(A)$ and lateral $(B)$ projections of left-carotid angiography, showing intracranial metallic fragment (arrows) in close proximity to anatomical course of ophthalmic artery

Homonymous hemianopia was encountered among patients who suffered from tangential skull wounds, penetrating, and through-and-through brain wounds. Associated neurological defects, namely dysphasia, perceptive deafness, and most commonly hemiparesis, were of relatively frequent occurrence among these patients. The treatment was like that for the missile wounds, that is by debridement. There was a tendency for the homonymous hemianopia like the other neurological defects to improve after this procedure, but in the more severely wounded patients the improvement was less. The severity of the hemiparesis was a good guide to prognosis; and those without hemiparesis later regained full vision.

Cortical blindness resulted from concussion injuries of the occipital cortex. In two cases of pure cortical blindness there was tangential injury of the occipital area. At operation 3 days after injury, bone fragments were removed from the surface of a blue but grossly intact dura mater. A thin layer of clotted blood was found over the contused occipital cortex when the dura mater was opened. Both patients fully regained their vision; in one, however, vision (described as cloudy) was beginning to return before the operation.

There were two other cases presumably of cortical blindness in which the dura mater was lacerated and the brain superficially penetrated. The patients sustained tangential wounds of the occipital area in which both occipital lobes were involved. They suffered from post-traumatic amnesia which lasted a few minutes; later, for the succeeding 3 days, they were totally blind. When they were examined at UCH a week after wounding, 
they both presented clinically with homonymous hemianopia. After debridement of their wounds, the hemianopia cleared, leading to restoration of the visual fields to near-normal, 4 weeks after operation. These patients were immediately lost to follow-up.

\section{(b) Neuromuscular abnormalities}

There were two cases of paralysis of the sixth cranial nerve and one of the third nerve. The two patients with sixth nerve palsy had tangential skull wounds of the parietal area, and ophthalmological examination showed that both had diminution of visual acuity in the ipsilateral eye. In one, the visual acuity improved to near normal 2 months after debridement of the head wound; in the other, the acuity deteriorated slowly but progressively after operation. The sixth nerve palsy persisted when the two patients were last seen in this hospital 3 and 5 months respectively after being injured.

The patient who presented with the complete ptosis had a penetrating brain wound caused by an intact bullet which entered the cranium at the left supraorbital region (Fig. 3 ). The ptosis was no doubt exaggerated by the atrophic, shrunken globe which had been damaged by the high velocity bullet which pierced the head close to the orbit.

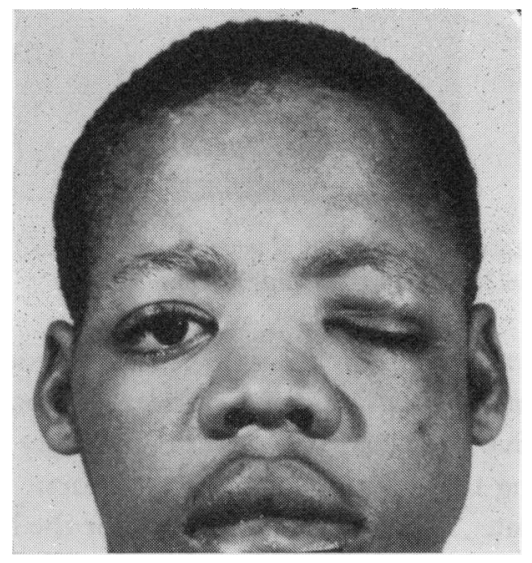

F I G. 3 Left orbito-facio-cranial penetrating wound, with ipsilateral ptosis

\section{(c) Post-concussional syndrome}

Three patients presented with features typical of the post-concussional syndrome: headaches, tinnitus, sensations of 'the eyes turning', and obscurations of vision especially in sunlight. The visual symptoms started 2 to 3 months after the injury. Ophthalmological examination showed that the eyes were essentially normal in all three cases; two of them, however, had spastic hemiparesis.

\section{(d) Epilepsy}

Three of the 3 I patients have so far shown the late type of post-traumatic epilepsy. One gave a history of a constant aura of transient amaurosis before his generalized epileptic attacks. He was a 28-year-old soldier, who suffered a penetrating right fronto-parietal missile head wound, and developed epilepsy 5 months later. 


\section{(e) Hysteria}

One 25-year-old soldier with a missile head wound of the occipital region was labelled as probably suffering from hysterical blindness. He had a small scalp wound which had healed when he was first seen here and skull radiographs were normal. He came to the neurosurgical clinic in a wheel-chair because he saw 'through a smoke' since his accident. A small scalp wound of the occiput had healed; the pupillary reflexes and the ocular fundi were all normal; there were no neurological defects and skull radiographs showed no abnormalities. He was presumed to be suffering from cortical blindness. Later, during ophthalmological consultation, he was given plain lenses and was successfully persuaded to read with the other eye. He was treated with librium, and within a fortnight, regained full vision.

\section{Discussion}

The occurrence of visual disturbance after missile head injury is not entirely unknown at Ibadan, Nigeria. Olurin (1970) reported 22 Nigerians who presented with cortical blindness at the Ophthalmological Clinic during a 5-year period. One of them (Case 6) was a 22-year-old patient with an antecedent missile head injury. However, our experiences with the victims of the civil war probably underestimate the true incidence of visual disturbance in missile head injury. With the long interval between wounding and arrival at University College Hospital, soldiers with progressive or massive intracranial haematoma (extradural or temporal lobe) and possible neuromuscular abnormalities would probably have died soon after wounding or in transit, and were therefore not seen here. It is also known that many visual defects are likely to recover spontaneously, so that if these patients are not examined soon after wounding, some instances of visual disturbances will be missed. In addition, because of limitation of time and opportunity, especially when the wounded arrive in large numbers, ophthalmological consultation could not be undertaken in all our patients with missile head wounds.

In the series of $25^{\circ}$ patients with missile head wounds treated in this hospital, more than half of the injuries were due to bullets. Among patients with visual disturbances, on the contrary, shrapnel accounted for more than 50 per cent of the casualties. It is of interest, in this regard, to note that, in the first world war, only 6 per cent of the eye casualties were due to blast, whereas in the second world war, when more effective explosives with greater capacity for fragmentation were employed, shrapnel caused up to 40 per cent of the visual injuries (Cope, 1953).

In penetrating missile head wounds, it is not always possible to be able to determine the exact site in the optical system of the lesion which is responsible for visual disturbance, especially in patients with homonymous hemianopia. Clinical detection of neurological defects and of the exact site of the wound are invaluable in this regard. In this series, the visual disturbances associated with orbito-facio-cranial injuries were often permanent. On the other hand, visual loss which resulted from injury to the optic radiation (Jepson and Whitty, 1947) and from concussion injury of the occipital cortex (Hine, I918) tended to show good recovery.

This study bears out previous war-time experiences (Calvert, I947) of the important and frequent association between oculo-facial wounds and head injuries. To obtain a better and more informative study of the visual sequelae of missile head wounds, it would be useful, whenever possible, to brigade an ophthalmologist with the neurosurgical unit. 


\section{Summary}

Visual disturbances were found in $3 \mathbf{I}$ Nigerians after missile head injuries. Visual loss from anatomical damage to the visual pathway predominated. The loss was permanent in peripheral lesions, but a reasonably good recovery was seen in lesions of the optic radiation and visual cortex.

\section{References}

Calvert, c. A. (1947) Brit. F. Surg., War Surgery Suppl. No. I, p.I 19 COPE, v. z. (ed.) (1953) "History of the Second World War-Surgery". H.M.S.O., London CRoss, A. G. (1945) Trans. ophthal. Soc. U.K., 65, 20 HINE, M. L. (1918) Brit. F. Ophthal., 2, 12 HOLMES, G., and LISTER, W. T. (1916) Brain, 39, 34 INOUYE, T. (Igog) "Die Sehstörungen bei Schussverletzungen der Korticalen Sehspäre". Engelmann, Leipzig

JEPSON, R. P., and whitty, c. w. M. (1947) Brit. F. Surg., War Surgery Suppl. No. I, p. 243 OLURIN, o. (1970) Afr. F. med. Sci., r, 357 SKeOCH, H. H. (1945) Brit. F. Ophthal., 29, I I 3

SMALL, J. M. (196r) Trans. ophthal. Soc. U.K., 81, 587

sYMONDS, C. P. (1945) Ibid., 65, 3

WiLson, K. (19I 7) Lancet, 2, I 